\title{
MOVIMIENTO FEMINISTA CHILENO Y VIOLENCIAS DE GÉNERO. CLAVES DE LECTURA PARA ENTENDER LA ACCIÓN COLECTIVA EN EL TIEMPO PRESENTE
}

Chilean feminist movement and Gender violence. Keys to Reading to UNDERSTAND COLLECTIVE ACTION IN THE PRESENT TIME

Fecha recepción: 6 de octubre de 2021 / fecha aceptación: 15 de noviembre de 2021

Fabiola Miranda Pérez y Maite Henríquez Olivares²

Cómo citar este artículo:

Miranda Pérez, F.y Henríquez Olivares, M. (2021). Movimiento feministachileno y violencias de género. Claves de lectura para entender la acción colectiva en el tiempo presente. Revista Pensamiento y Acción Interdisciplinaria, 7(2), 46-63. https://doi.org/10.29035/pai.7.2.46

\section{Resumen}

Nosotras, las mujeres, nos hemos movilizado por nuestros derechos desde tiempos remotos. En algunas ocasiones de manera más pública y, en otras, desde lo oculto. Por medio de la revisión de documentos históricos, buscamos reflexionar sobre la conformación del movimiento feminista chileno y la integración de la problemática de las violencias contra las mujeres a partir de una aproximación específica: las relaciones entre las actoras sociales en lucha por la democracia y una vida libre de violencias, tanto a nivel de los debates y formulaciones teóricas planteadas en su seno, como en sus repertorios de acción. En particular este artículo aborda el movimiento de mujeres en tiempos de la dictadura pinochetista y sus continuidades respecto al movimiento social del Mayo Feminista de 2018.

Palabras clave: Feminismos, movimientos sociales, politización, subjetivación colectiva, violencia de género

1 Cientista política, magíster en políticas públicas y cambio social y doctora en ciencia política, académica Universidad Alberto Hurtado, Santiago de Chile. Correo electrónico: fmiranda@uahurtado.cl

2 Socióloga, diplomada en Políticas sociales: Desarrollo y pobreza, Universidad Alberto Hurtado, Santiago de Chile. Correo electrónico: maitesolhenriquez@gmail.com 


\begin{abstract}
We, women, have been mobilizing for our rights since ancient times. In some occasions publicly and, in others, in a more hidden way. Through the review of historical documents, we seek to reflect on the establishment of the Chilean feminist movement and the integration of the issue of violence against women in the field, based on a specific approach: the relations between social actors in the struggle for democracy and a life free of violence, both at the level of debates and theoretical statements raised within it, as well as in its repertoires of action. In particular, this article addresses the women's movement in times of the Pinochet dictatorship and its continuities with respect to the Feminist May 2018 social movement.
\end{abstract}

Keywords: Feminisms, gender violence, social movements, politization, collective subjectivization.

\title{
Introducción
}

Las violencias ejercidas hacia las mujeres por parte de sus parejas en la historia y, en específico en el contexto chileno, han sido poco estudiadas desde una perspectiva histórica. Pese a existir fuentes para el análisis, este tema quedó reducido a un mero marco contextual y, hasta entrados los años 80 , no fue parte de una agenda de investigación de las ciencias sociales.

En relación con la problemática de las violencias conyugales, ha habido durante gran parte de la historia un cierto grado de tolerancia social. Por esta razón, durante muchas décadas no fueron abordadas como un problema público (Miranda Pérez, 2017). No fue hasta los años 80 , gracias al movimiento de mujeres de oposición a la dictadura, que esta temática comenzó a tomar relevancia. Si bien se trataba de una situación conocida por todos y todas, al mismo tiempo era gran parte del tiempo naturalizada socialmente y más bien tratada como un tabú. Así, su discusión fuera del ámbito privado y, luego, su tratamiento en tanto que problema público (Subirats, 2001) es parte de nuestra historia reciente. Es más, no fue hasta los años 90 que podemos hablar de intentos de coordinación de una política pública que apuntó al problema de las violencias conyugales, y más bien las familiares, dentro del contexto del hogar.

La reciente problematización pública, por parte del movimiento de mujeres, de las violencias en las relaciones conyugales no significa que no hayan existido mujeres organizadas durante todo el siglo XX. La organización de mujeres tiene larga data. En efecto, podemos encontrar diferentes agrupaciones de mujeres de tipo político formal, tales como el Partido Cívico Femenino (1922), Partido Demócrata Femenino (1924), Unión Femenina de Chile (1928), Agrupación Nacional de Mujeres (1934). Todas organizaciones que generaron grandes avances en la discusión sobre los derechos civiles y políticos de las mujeres. El Movimiento por Emancipación de la Mujeres de Chile (MEMCH), fundado en 1935, a diferencia de sus precedentes, comenzó a disputar los espacios masculinizados de la política 
de una manera mucho más generalizada en el país (Vitale, 1996; Rojas y Jiles, 2019). Por otro lado, podemos encontrar agrupaciones de mujeres de tipo político informal, como la Sociedad Mutualista Femenina (1887), Unión en Resistencia de Tejedoras (1906), Asociación de Protección Mutua de la Mujer (1906), entre otras, las que, desde diferentes ámbitos, impulsaron la problematización por la vida de las mujeres y sus familias. Por ejemplo, realizaron la toma de terrenos en la lucha por conseguir mejores condiciones de vida, tal como lo fueron las tomas que dieron origen a la población La Victoria y Santa Adriana (Vitale, 1996).

No fue hasta los años 80 que las violencias de género dentro de la pareja lograron ser reinterpretadas por un cierto abanico de mujeres. Por un lado, quienes sufrían la represión política del día a día, que vieron desaparecer a sus familiares y buscaron agruparse entre ellas conformando redes de solidaridad. Por otro, quienes partieron al exilio y volvieron. Conocidas como "las retornadas", muchas de ellas provenientes de países del norte, se pudieron vincular con la Academia en sus pasos, donde a partir de sus propios cuadros de interpretación de la realidad y en confluencia con discursos que se fueron expandiendo dentro del continente latinoamericano, comenzaron a problematizar colectivamente las violencias hacia las mujeres (Sanz-Gavillon, 2014). A partir de esto, proponemos un breve análisis de la constitución de las violencias conyugales en cuanto a la construcción de subjetividades y repertorios de marcos de acción colectiva.

Nos interesa mirar cómo ciertos contextos, en este caso de represión, pueden ser impulsores de una dimensión política de problemas que permanecieron por mucho tiempo dentro de la esfera privada. Así, nos preguntamos: ¿qué impulsa a las mujeres a organizarse frente a las violencias de género en el marco de contextos de opresión? Y ¿cuáles son los repertorios de acción movilizados por ellas frente a la problemática? Para nosotras, la experiencia de las violencias y el reconocimiento en la otra son un motor en común que reúne a las mujeres en su conceptualización y movilización. En particular, buscamos describir cómo se configura el problema de las violencias de género hacia las mujeres durante la dictadura pinochetista (1973-1989), reconociendo repertorios de acción colectiva utilizados por ellas en el marco de la opresión política. Finalmente, analizamos la influencia del reconocimiento de la otra en la colectivización de un problema hasta entonces tratado como algo relativo a la esfera privada.

Con todo, nos interesa reflexionar cómo esta historia reciente nos lleva a pensar en la existencia de procesos dialécticos donde temáticas que, aun cuando han estado enclaustradas en lo privado, terminan colectivizándose, incluso más allá de sí mismas. A nuestro parecer, este ha sido un motor que ha impulsado el resurgimiento del movimiento feminista chileno del tiempo presente. En este sentido, creemos que considerar la historia reciente nos ayuda a comprender si existen fracturas, continuidades o discontinuidades del movimiento feminista chileno.

Siguiendo esta pauta de análisis, metodológicamente el corpus documental que abarca este artículo comprende fuentes secundarias de carácter bibliográfico, 
en base a una colección de artículos y tesis de autoras y autores chilenos recuperados de la Biblioteca Nacional y archivos de la Biblioteca de la Universidad de Academia Humanismo Cristiano. Por otro lado, se utilizan fuentes primarias de época correspondientes a documentación del MEMCH durante su segunda fase (década 1980).

\section{Las mujeres y la solidaridad}

En 1970 Salvador Allende ganó las elecciones presidenciales, siendo el primer presidente socialista electo por la vía democrática. Durante su gobierno se implementaron políticas que pretendían el cambio social, económico y político de Chile, otorgándole un papel más importante al Estado como regulador. Así, se apostaba a una repartición más igualitaria de la riqueza y el mejoramiento de las condiciones de vida de las personas, para eliminar las desigualdades económicas que dejaban a las clases populares en una creciente pauperización y vulneración de derechos (Garcés, 2013; Bowen Silva, 2008; Vidal, 2014). El 11 de septiembre de 1973, la derecha con la ayuda de las Fuerzas Armadas Ilevaron a cabo el golpe de Estado contra el gobierno de la Unidad Popular, poniendo en el poder a Augusto Pinochet. Este hecho trajo consigo no solo la represión y persecución de quienes habían sido parte del gobierno de la Unidad Popular, sino de todos aquellos que se oponían a la dictadura. Asimismo, vino la instauración progresiva del modelo económico neoliberal, la privatización del mercado y de las políticas sociales (Gárate, 2012). Con todo, los avances que se podrían haber visto vislumbrados quedaron frustrados: ciertos grupos históricos y, en particular, las organizaciones de mujeres fueron desarticulados desde sus bases, provocando una repentina dislocación entre el tejido social y los actores y las actoras políticos tradicionales, llevando al país a una crisis política y social.

La refundación del Estado que buscaba la dictadura tuvo implicaciones no solo en orden económico y político, sino también en lo social y, específicamente, en las relaciones de género (Kirkwood, 1986). La política conservadora de la familia tradicional (madre, padre e hijos), imperante en este contexto, consideró a las mujeres como el pilar de la reproducción de la familia, de las costumbres, la tradición y los valores. Por esta razón, serían las principales encargadas de llevar a cabo las transformaciones socioculturales que pretendía la dictadura (Zamora, 2008; Valdés, 1987). Así, tal como ocurrió en otros períodos históricos, el Estado buscó moldear la conformación de la identidad de las mujeres (Rosemblatt, 1995; Zárate, 2008). Al convertirse en un instrumento de divulgación de los valores del nuevo orden estatal (Zamora, 2008), fueron disciplinadas siguiendo el rol materno de educar y proteger al hogar y a los hijos. Estos mensajes fueron principalmente transmitidos por los medios de prensa, por los centros de madres (CEMA-Chile ${ }^{3}$ ) y la educación y reproducción de los nuevos valores del Estado y de la familia (Godoy, 2013).

3 Fundación que estaría a cargo de Lucia Hiriart, esposa de Augusto Pinochet. 
En este contexto, las mujeres no solo estaban siendo dominadas en lo político, en la medida en que eran las guardianas del orden y la patria. También en lo económico, como consumidoras de un mercado potenciado por el aumento del sector de servicios y comercio, y como trabajadoras al alero de una incorporación al sector informal de la economía que las dejaba bajo precarias condiciones de trabajo y remuneración. Las mujeres, por lo tanto, fueron sobreexplotadas al ser el sostén de la economía y de las familias, lo que especialmente se veía reflejado en el discurso del ser buena madre: "sus hijos están por sobre todo y ellas comienzan a desarrollar las actividades más increíbles con el objeto de obtener algún ingreso" (Valdés, 1987, p. 10). Así era reforzada la histórica doble jornada de trabajo que debían desarrollar las mujeres, una remunerada por lo laboral y otra no remunerada en lo doméstico.

En palabras de Valdés (1987), las mujeres tuvieron el rol de afirmar la dictadura, donde el ser buena madre y protectora de la nación se entroncaba con las políticas del terror y represión de los cuerpos, combinado con la despolitización de la política. Las mujeres cumplían con la protección de los suyos al poner freno a la participación en las acciones colectivas de oposición a la dictadura, dado que en estas instancias sus hijos, maridos y familiares podían ser apresados, torturados o desaparecidos.

A pesar de este discurso, la acción colectiva y resistencia en contra de la dictadura fue desde el inicio llevado a cabo por el movimiento de mujeres (Miranda Pérez y González, 2018). Aunque eran las principales sujetas de afirmación del orden, no quedaron ajenas a lo que acontecía en el país. En efecto, igualmente ellas y sus familiares sufrían de la represión política y económica. En un comienzo, el movimiento de mujeres de oposición enfocó sus fuerzas contra la violación de los Derechos Humanos, debido a la masiva represión, tortura, aprisionamiento y desaparición, más aún en los primeros meses. Pero, más que remitir a una acción espontánea, la creciente neoliberalización del país y todas las consecuencias que trajo consigo en el orden de lo social, político, económico y cultural, llevó a la conformación de un movimiento que, en palabras de Touraine, será entendido como "el conjunto de acciones conflictivas tendientes a transformar las relaciones de dominación ejercidas sobre los recursos culturales" (citado en Espeche, 2012, p. 8).

Los diferentes grupos de mujeres se fueron conformando no solo para expresar su solidaridad con las víctimas, también para luchar por su descontento en torno de la salud, la alimentación, el desempleo, los derechos legales de las mujeres y trabajadores, la pobreza y la violencia doméstica. La lucha por la democracia, en ese sentido, también incorporó la lucha por la igualdad y la justicia en todos los espacios de la vida social.

Las mujeres aquí ya se han organizado como movimiento ante la represión política, el hambre, la violencia. En suma, situaciones que generan solidaridades y 
que permiten reconocernos entre y como mujeres, más allá de la clase. Esto lleva a un número importante de mujeres, algunas asociadas a las iglesias (principalmente la católica), a las ollas comunes y, con ello, a otras familias víctimas de la represión, generándose así nuevas solidaridades y organizaciones. Por lo tanto, las mujeres se posicionaron como actoras sociales emergentes, quienes se vieron enfrentadas a las consecuencias sociales de la política pública (Garate, 2012). De esta manera, y estando vinculadas con las izquierdas, surgió el "pensamiento y la identidad feminista" (Ríos Tobar et al., 2003). En definitiva, los repertorios propios de los nuevos movimientos sociales fueron dialogando con las diversas problemáticas que sujetaban a las actoras. Es allí donde encuentran redes de solidaridad y se reconocen entre ellas mismas.

Durante este periodo se crean dos caras del movimiento de mujeres. Un lado más académico, representado por el Círculo de Estudio de la Mujer (CEM), el cual estaba compuesto principalmente por mujeres que habían apoyado el gobierno de la Unidad Popular (1970-1973) y, por lo mismo, partieron al exilio a inicios de la dictadura. Ellas fueron espectadoras del feminismo en el resto del mundo, principalmente en países del Norte. Así, a su regreso a Chile, las llamadas "retornadas" dieron paso a un nuevo proceso de militancia feminista, el que también incluyó la afiliación de mujeres populares. Más que un quiebre en la relación de los tipos de conocimientos, se unen entre sí para caracterizar de manera conjunta el problema de las violencias de género. En un principio sobre la violencia política, es decir, aquella violencia producto del régimen dictatorial, especialmente vivenciada en sectores populares y contra los opositores y las opositoras de la dictadura; luego sobre las violencias conyugales, a partir de la desnaturalización de las violencias ejercidas hacia las mujeres en el marco de sus relaciones íntimas, generando una producción importante de estudios críticos sobre la temática (Sanz-Gavillon, 2014). Lo relevante de esto último es que existe un movimiento por los Derechos Humanos, donde el movimiento de las mujeres se comenzó a afirmar como colectivo que hace frente al régimen dictatorial.

Algo importante del movimiento de mujeres de este periodo es que construyó un discurso sobre lo que debería ser la democracia, proveniente de las bases y que utilizó referencias como el pensamiento de Kirkwood (1986), quien consideraba el género como un componente vital para pensar una democracia. Por su parte, también aportó y se nutrió del movimiento feminista latinoamericano (Forstenzer, 2012), desde donde se fueron construyendo reflexiones sobre las relaciones de dominación, además de marcos interpretativos sobre lo que significaban las violencias hacia las mujeres. Este panorama tuvo repercusiones en la Transición, momento en que las políticas públicas y los organismos de Estado comenzaron a impulsar todo un discurso respecto de la violencia conyugal. 
Movimiento feminista chileno y violencias de género. Claves de lectura para entender la acción colectiva en el tiempo presente por Fabiola Miranda Pérez y Maite Henríquez Olivares

\section{Feministas organizadas}

La agrupación de mujeres siguió las lógicas de los nuevos movimientos sociales (NMS), dando centralidad a las reivindicaciones de justicia y dignidad, identificando las nuevas formas de opresión del neoliberalismo. Así, la lucha ya no era solo de clase, sino también por el bienestar, la calidad de vida, la igualdad y la justicia social (Mejías y Suárez, 2015).

Un ejemplo es la Agrupación de Mujeres Democráticas (AMD), fundada en octubre de 1973. Ellas se reunían, en un inicio, para apoyar a las familias de detenidos desaparecidos: entregaban información, generaron espacios para la organización, fueron mensajeras entre los presos políticos y sus familias, como también brindaron alimento a las familias y formaron instancias de esparcimiento para los niños de las aquellas familias (Gross, 2015). Denominándose un movimiento "voluntario, unitario y solidario" (Agrupación de Mujeres Democráticas, 2015), no solo defendieron la lucha por los Derechos Humanos, también la "lucha por los postergados derechos de la mujer en los aspectos legales de la salud, trabajo, culturales y participación social y política" (Agrupación de Mujeres Democráticas, 2015). Igualmente, buscaban modificar las leyes de matrimonio, la privatización de la economía y la Constitución política.

Los horizontes de AMD abordaban todas las opresiones que eran producto de la dictadura. Ellas veían que la importancia de las mujeres en la lucha antidictatorial era esencial, ya que cumplían un rol unitario como defensoras de la vida, a propósito de su rol maternal. De esta manera, se apropiaron de los discursos de la dictadura sobre la mujer y lo subvirtieron hacia la liberación de la violencia de género.

\section{Figura 1}

Reunión de la Agrupación de Mujeres Democráticas (AMD), fundada en octubre de 1973, para la defensa de los derechos humanos. ARNAD, Fondo Fortín Mapocho.

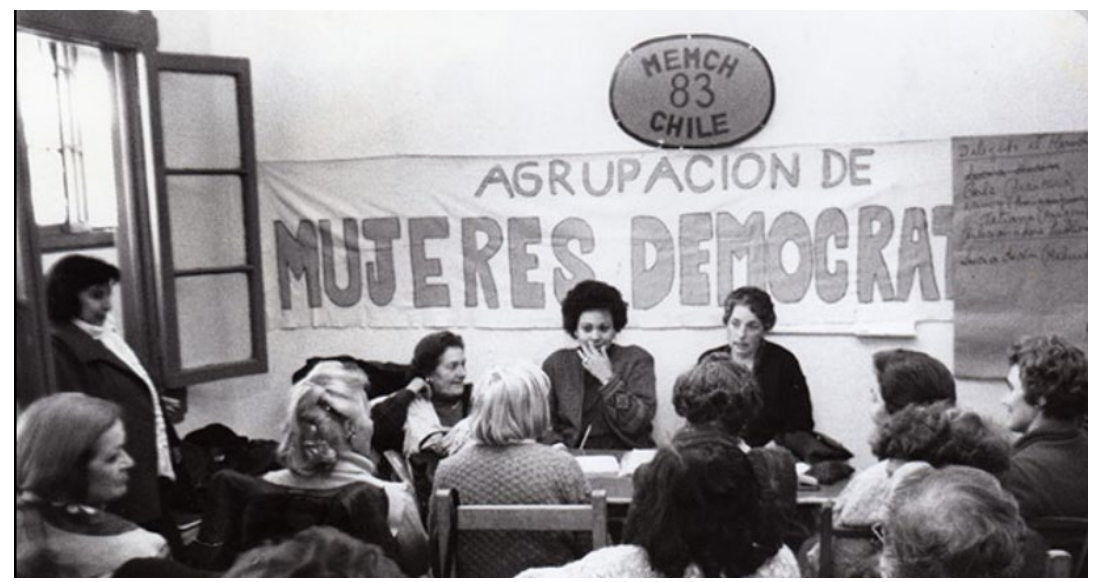

Fuente: Servicio Nacional del Patrimonio Cultural- https://www.archivonacional.gob.cl/ 
La mayoría de las mujeres de la Agrupación eran militantes del Partido Comunista y del Partido Socialista, quienes no solo criticaban las prácticas de la política tradicional, también apelaban a una mayor horizontalidad en la organización (Gross, 2015). De esta forma se articulaban bajo repertorios que hacían sentido en el reconocimiento de la otra como par. Por su parte, la conformación de redes con otros colectivos nacionales de mujeres y de familiares de detenidos desaparecidos era igualmente importante para el movimiento de oposición. Así, por ejemplo, se fueron generando lazos entre MEMCH 83, las Agrupaciones de Familiares de Detenidos y Desaparecidos y de Presos Políticos y la Asamblea de Civilidad.

Otro colectivo de mujeres que se conformó en 1983, tras la muerte de Sebastián Acevedo ${ }^{4}$, fue la organización Mujeres por la Vida. A través de la carta abierta "Hoy y no Mañana", declararon su oposición a la dictadura, denunciaron la represión política y la violación de los Derechos Humanos y abogaron como fin la restauración de la democracia. Al igual que AMD, también apostaron a la lucha por el mejoramiento de las condiciones de vida de la mujer y de sus hijos, bajo el entendido de que las mujeres, como defensoras de la vida, serían las principales protectoras de la nación. Asimismo, apuntaban a la igualdad entre hombres y mujeres, por la igualdad en el país y en el hogar, enfocando sus demandas igualmente en los planos económico, jurídico y social. Entre sus repertorios de acción, se encontraba la organización de marchas pacíficas, encuentros nacionales de mujeres por la vida, ollas comunes, panfletazos, vigilias y visitas a los presos políticos, entre otras. Por su parte, Mujeres por la Vida mantuvo vínculos con otras agrupaciones, como la AMD, MEMCH 83, las Agrupaciones de Familiares de Detenidos-Desaparecidos, de Presos Políticos, de Relegados y de Ejecutados (Gross, 2015). Al igual que la AMD, se estructuraba de una forma no jerárquica y no partidaria, donde la igualdad era lo primordial al interior de la organización.

Estos ejemplos de las agrupaciones que conformaban el movimiento de mujeres anti-dictatorial nos permiten ver las diferentes dimensiones a través de las cuales los NMS se articularon para la defensa de sus intereses. Una de estas fue la autonomía respecto del Estado y los partidos políticos, para así lograr la autonomía material y simbólica. Los repertorios de acción de la organización de mujeres en dictadura, más que orientarse por partidos políticos, pasaron por la acción comunitaria no institucional, basada en la relación horizontal y simétrica. Otro aspecto nos remite a la conformación de las redes de solidaridad. Por ejemplo, en el plano económico, por medio de las ollas comunes o en los talleres realizados a niños y mujeres.

Este panorama nos lleva a considerar un segundo momento del movimiento de mujeres, la reflexión no solo sobre la violencia política de la dictadura, sino también sobre aquellos componentes tan vitales como la libertad y la igualdad para la

4 Sebastián Acevedo Becerra, obrero, y militante comunista, quién tras la desaparición de sus dos hijos, en su desesperación y sin respuestas el 11 de noviembre se inmola frente a la Catedral de Concepción. 
Movimiento feminista chileno y violencias de género. Claves de lectura para entender la acción colectiva en el tiempo presente por Fabiola Miranda Pérez y Maite Henríquez Olivares

democracia. Estos planteamientos se nutrieron de las relaciones que conformaron el movimiento local de mujeres con el feminismo internacional, especialmente en torno a las "reivindicaciones sexo-género" (Prudant Soto, 2013, p. 44). Particularmente, la AMD estableció relaciones con redes feministas internacionales durante los años 80, apoyando a las agrupaciones de mujeres de Guatemala, Costa Rica y República Dominicana. Con todo, se fue dando paso a desmantelar "el cuadro ideológico discursivo del régimen, así como la política de represión en la que se basó, poniendo en evidencia las contradicciones fundamentales a partir de las cuales [el régimen] operaba" (Prudant Soto, 2013, p. 44).

\section{Agrupación y reflexión ante la represión}

La dictadura pretendía el desarme de la politización de la sociedad. Durante la primera ola de implementación del nuevo modelo económico, el terrorismo de Estado y el neoliberalismo confrontaron la radicalidad de los movimientos populares y, finalmente, el disciplinamiento terminó por aniquilar la organización política (Espeche, 2003). La acción colectiva, entendida como la confluencia de personas por la defensa de intereses particulares, ha sido una práctica que las mujeres han desarrollado a lo largo de la historia, tal como hemos revisado hasta el momento. En tiempos de dictadura fueron ellas quienes pusieron sobre la palestra la lucha de género. Y, con ello, levantaron demandas por la defensa de la vida, orientadas a la igualdad en todos los planos de la vida social, no solo a la represión política que sufrían tanto hombres como mujeres.

El movimiento de mujeres de este período fue nutrido por aquellas mujeres militantes y teóricas feministas. Especialmente las "retornadas", quienes fueron partícipes del CEM, creado en 1975 y apadrinado por la Academia de Humanismo Cristiano. Este centro estaba compuesto por un grupo de investigadoras que trabajaban en la producción de una reflexión teórica feminista. Este tipo de relaciones en el movimiento dio paso a una reflexión sobre un nuevo marco interpretativo respecto a las violencias contra mujeres, el que se planteó dentro un sistema de dominación masculina que era igualmente reproducido y avalado por el autoritarismo de la dictadura (Sanz-Gavillon, 2014). De esta manera, bajo el eslogan creado por Julieta Kirkwood en 1985, "iDemocracia en el país y en la casa!", se comprendía el campo de la dominación de las relaciones de género -tradicionalmente consideradas en el marco de lo privado- como un asunto público estrechamente relacionado con la lucha por la democracia.

Este marco analítico sobre las violencias de género y la democracia dio paso a la creación de una serie de organizaciones feministas, como el Comité por los derechos de la mujer (CODEM) y el Movimiento de Mujeres Pobladoras (MOMUPO). Asimismo, aquellas asociadas a la Vicaría de la Solidaridad ${ }^{5}$. De esta

5 La Vicaría de la Solidaridad, dependiente del Arzobispado de Santiago, tuvo un importante rol en la lucha contra la dictadura, propiciando recursos humanos, jurídicos e infraestructura para las familias de detenidos desaparecidos. 
manera, se propició un contexto de debate y reflexión entre mujeres militantes, del mundo académico y popular, donde, pese a las discrepancias, Iograron posicionar la problemática de la violencia conyugal y doméstica como un movilizador que permitía la agrupación entre mujeres.

Sumado al contexto internacional, el debate sobre la violencia sufrida por las mujeres permitió la emergencia de repertorios de acción colectiva y de organización. Durante los años 80 , las manifestaciones sociales por la restauración de la democracia dieron paso a la negociación con actores políticos en favor de dicho proceso, especialmente desde 1986. Este proceso culminó en 1988 con el plebiscito que permitió terminar con la dictadura, a partir de lo cual se comenzó a generar un panorama político de cambio e integración sobre lo que sería la Transición, donde las iniciativas de las organizaciones de mujeres fueron igualmente presentadas en el debate público del plebiscito (Araujo et al., 2000).

Las diversas ideas e iniciativas de las organizaciones feministas fueron incorporadas por la Concertación de Partidos por la Democracia ${ }^{6}$. El debate sobre las múltiples interpretaciones y urgencias a las que debía hacer frente el país, planteadas por esta naciente coalición, fue alimentado por las propuestas de las problemáticas de género y de la violencia doméstica. En efecto, estos temas comenzaron a ser ampliamente percibidos por el resto de los partidos políticos como una demanda del terreno de lo público (Araujo et al., 2000).

De esta manera, feministas independientes y militantes conformaron la Concertación de Mujeres por la Democracia. Así, buscaban incluir en el debate público las problemáticas de género, haciendo visible a las mujeres como sujetas políticas y, por lo tanto, como actoras fundamentales en la transición a la democracia. Por otro lado, estas mujeres fueron parte de la Red Latinoamericana Contra la Violencia Doméstica y Sexual, lo que no solo les dio una mayor visibilidad. Asimismo, les permitió sumarse a las temáticas que eran demandadas por las feministas del resto de la región. Con todo, este grupo tuvo incidencia en la elaboración del programa de mujeres en 1988, desde donde se legitimaron las demandas del movimiento feminista.

Un aspecto importante por destacar es la relación del movimiento de mujeres con el feminismo internacional y latinoamericano. La incorporación de aquellas agendas permitió nutrir y levantar marcos interpretativos nacionales, referentes al maltrato contra las mujeres en el espacio doméstico (Montecinos, 2003; Marugán y Vega, 2001). En este marco, la implementación de la Convención para la eliminación de todas las formas de discriminación hacia las mujeres de 1979 (CEDAW, por sus siglas en inglés) impulsó no solo las primeras campañas de sensibilización sobre este problema, también la realización de cuatro conferencias sobre las mujeres. En estos espacios, las organizaciones y la comunidad internacional denunciaron la represión política y las condiciones de sumisión

6 Coalición de partidos de centro-izquierda que gobernó de manera interrumpida entre los años 1990 y 2010. 
que vivían las mujeres en la dictadura chilena (Conferencia de México sobre la Mujer, artículo 34 de la declaración adoptada en la Convención). Particularmente, la Conferencia de Copenhague de 1980 fue un hito para la articulación del movimiento feminista nacional con las redes internacionales (Marques-Pereira, 2012), pues permitió al año siguiente su participación en el primer encuentro feminista de América Latina y el Caribe, realizado en Bogotá (1981). Allí se creó la campaña internacional de lucha contra la violencia machista (Sanz-Gavillon, 2014). Este paso de ideas y de repertorios de acción permitió complejizar el marco analítico del movimiento nacional de mujeres respecto a las violencias conyugales, lo que finalmente se expresó en la incorporación de esta temática en las políticas públicas de la Transición.

\section{Figura 2}

Portada Boletín Isis Internacional $n^{\circ} 9$ sobre Primer Encuentro Feminista Latinoamericano y del Caribe, julio de 1981, en Bogotá, Colombia. AMG, Fondo Isis, Caja 536.

\section{Boletín Internacional de las Mujeres}

9

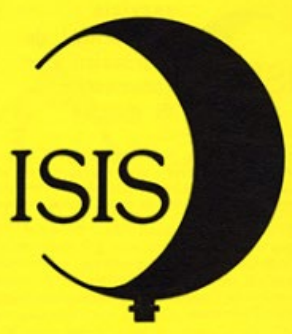

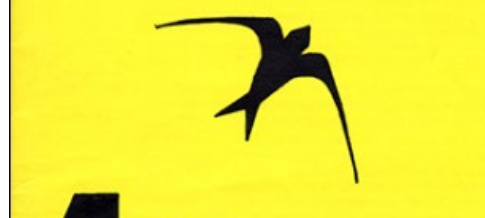

er

ENCUENTRO FEMINISTA

LATINOAMERICANO

Y DEL CARIBE

BOGOTA - COLOMBIA

Fuente: Servicio Nacional del Patrimonio Cultural- https://www.archivonacional.gob.cl/ 


\section{Mayo feminista: feministas contra la violencia patriarcal}

La Transición derivó en la institucionalización de un grupo de mujeres provenientes de los movimientos de oposición a la dictadura. La profesionalización de las feministas en los espacios estatales, las ONGs y los centros de investigación opacó -en lo público- a aquellas feministas que se agruparon en otro tipo de espacios de acción colectiva (De Fina y Figueroa, 2019). En este sentido, pese a que se ha hablado de un "silencio feminista" (Ríos Tobar et al., 2003; Saavedra y Toro, 2018), Forstenzer (2019) precisa que, más bien, se trata de un ocultamiento de los diferentes movimientos de mujeres lo que habría caracterizado la década de 1990 y 2000. Ejemplo de aquello han sido las múltiples agrupaciones y colectivos feministas autónomos y militantes (Ríos Tobar et al., 2003; De Fina y Figueroa, 2019), donde cada cual, con repertorios de acción diferentes, siguen organizándose desde un plano territorial.

La escisión del movimiento feminista fue entre aquellas feministas "institucionales" que trabajaban en el Estado (especialmente, quienes estuvieron implicadas en la puesta en marcha del Servicio Nacional de la Mujer en 1991) y quienes continuaron trabajando de manera independiente, autónoma, a las autoridades estatales y desde las bases sociales. De este abanico, el Estado privilegió la profesionalización de las feministas. Consiguientemente, el discurso elaborado en la década precedente en torno de los roles de género se transformó en discursos asociados al cumplimiento de metas de gestión pública (Miranda Pérez y Godoy Hidalgo, 2013, 2016). Así, se fue perdiendo la fuerza del desarrollo político que se había previamente alcanzado, al contar con menor participación de las agrupaciones feministas (Saavedra y Toro, 2018; Forstenzer, 2019; Ponce, 2020).

Los movimientos estudiantiles de 2006 y 2011, en Chile, son los hitos que marcaron el paso al mayo feminista de 2018 (Ponce, 2020), donde miles de mujeres universitarias y secundarias se manifestaron públicamente. En un inicio, ante los casos de violación, abuso y acoso sexual al interior de los espacios educacionales. Luego, para también hacer un fuerte cuestionamiento sobre las condiciones de subordinación de las mujeres y disidencias sexuales. La crítica al neoliberalismo y el patriarcado tuvieron lugar en los análisis del llamado "Mayo feminista" (Saavedra y Toro, 2018), pues las manifestaciones y petitorios de estudiantes, excediendo el espacio de las universidades, se articularon con las diversas demandas de arraigo histórico del movimiento feminista. Entre otras, el reconocimiento del trabajo doméstico y de cuidados, la participación de las mujeres en los espacios políticos, la condena y penalización de las violencias sexuales y el acoso y el establecimiento de una educación no sexista. Asimismo, en materia de derechos sexuales y reproductivos y de autonomía corporal, donde el aborto tomó especial relevancia dentro del movimiento y en un país donde este no es de libre acceso.

El mayo feminista inició con la toma -de los edificios- de la Facultad de Humanidades de la Universidad Austral de Chile, como protesta contra el abuso y 
acoso sexual. Luego, una seguidilla de más de 20 universidades y establecimientos educacionales secundarios que se sumaron a la movilización, en solidaridad ante las mismas situaciones vividas en sus respectivos espacios. En este contexto, se realizaron asambleas de mujeres autoconvocadas, algunas incorporando a hombres, otras bajo un carácter separatista en conjunto con diversidades sexuales y de género. De este modo, siguió un arduo debate respecto a las vivencias de las mujeres y disidencias en los espacios públicos y privados.

De aquella catarsis de emociones, derivada del compartir vivencias de violencia en asambleas y en redes sociales, se dio paso a la sensibilización y la toma de conciencia. Este fue el motor movilizador para mujeres y disidencias, actores que por décadas habían sido invisibilizados, normalizados y ocultados ante la sociedad ${ }^{7}$. Gracias a este encuentro, un número importante de situaciones de abuso, que estaban confinadas en el campo del tabú, dio a relucir el carácter recurrente y generalizado de las violencias de género (Ponce, 2020).

Con todo, las mujeres y disidencias del mayo feminista tomaron como recursos sus propios cuerpos y experiencias cotidianas para denunciar las situaciones de abuso. Consignas, carteles, gritos y pancartas llenaron no solo los espacios educacionales, sino también las calles y los territorios (Urzúa Martínez, 2019). Tal como comenta De Fina y Figueroa (2019), "en muchos rincones a lo largo del país, el 'feminismo' se volvió tema y palabra corriente. De los gritos sofocados y contenidos por décadas, las jóvenes chilenas lograron liberar con fuerza estruendosa todo el peso de las violencias de género que las aplastan" (pp. 55). En efecto, muchas de las mujeres y disidencias que participaron de las movilizaciones lo hacían por primera vez de manera activa en el debate y análisis de lo político.

En universidades estatales y privadas se crearon "Secretarías de Género" y "Asambleas feministas autoconvocadas". Sumándose a las federaciones estudiantiles y coordinadoras de estudiantes, lograron llevar a cabo mesas de trabajo para la creación de protocolos de género, estableciendo un marco institucional de prevención y sanción del acoso y abuso sexual. Igualmente, se sumaron una serie de demandas en torno a una educación no sexista, como el cambio de nombre social en las credenciales universitarias, el uso de lenguaje inclusivo, la paridad en las cuotas de estudiantes y docentes e, incluso, en la bibliografía de los programas de estudio. Pese a que estas medidas estuvieron sujetas a las decisiones de cada universidad, llegaron al debate público una multiplicidad de demandas de los movimientos feministas en pos de una vida libre de violencias en todos los aspectos.

\footnotetext{
7 Véase más en Sepúlveda, P. (13 de mayo de 2019). A un año del mayo feminista que remeció Chile, ¿cuál es su legado? La tercera. https://www.latercera.com/que-pasa/noticia/mayo-feminista-en-chile/648290/; Estado Nacional. (s/f). Araceli Farías y movimiento feminista: "Los hombres no están llamados a no participar". 24horas. https:// www.24horas.cl/programas/estadonacional/araceli-farias-y-movimiento-feminista-los-hombres-no-estan-llamados-a-noparticipar-2718239; Velasquez, F. y Ortega, E. (12 de mayo de 2018). Viaje al centro de las tomas feministas. La tercera. https://www.latercera.com/reportajes/noticia/viaje-al-centro-las-tomas-feministas/162021/
} 
En continuidad con los procesos históricos, el movimiento feminista del 2018 incorporó diferentes líneas del feminismo, si bien desde el cuestionamiento de la violencia patriarcal hacia las mujeres y disidencias sexuales. Pese a las divergencias entre las diferentes agrupaciones, la conformación de coordinadoras y colectivos tuvo espacio en la unificación de demandas (Reyes-Housholder y Roque, 2018).

El movimiento feminista chileno se ha caracterizado por su vínculo con el movimiento feminista internacional. En plena globalización, el intercambio en conferencias de la Mujer de Naciones Unidas, la incorporación a organizaciones regionales y el mismo contacto entre mujeres han permitido generar diálogos y solidaridades con las feministas de otros países de la región. El movimiento "Ni una menos", la marea verde por el aborto, el caso de la manada en España, además de un sinfín de otras manifestaciones, expresan el sentimiento global por el fin de la violencia contra las mujeres y las disidencias sexuales (Reyes-Housholder y Roque, 2018; Forstenzer, 2019). En efecto, "el carácter global del movimiento es uno de los elementos centrales para generar movilización y desatar el descontento de las activistas" (Ponce, 2020, p. 1565). Así, los movimientos feministas en sus distintas escalas han impulsado la lucha por la transformación del campo social. En este desarrollo, los múltiples repertorios de acción han sido compartidos y situados respecto de las demandas nacionales y globales, lo que se ha sumado a las continuidades históricas en la agrupación de las mujeres, la colectivización de las experiencias de violencia y los cuestionamientos al patriarcado (De Fina y Figueroa, 2019).

\section{Conclusiones}

A través de este breve recorrido histórico hemos podido observar cómo las organizaciones de mujeres y feministas en Chile se han articulado en torno a la problemática de las violencias de género en las últimas décadas. Hemos podido visualizar que, pese a los distintos contextos analíticos, existen ciertos cuadros comunes de organización colectiva, los que han reactivado las demandas de las mujeres no solo sobre el reconocimiento de sus derechos, sino, asimismo, sobre las reivindicaciones por espacios libres de violencias en el sistema social y económico neoliberal, generando un proceso de subjetivación colectiva en torno a la problemática.

Un aspecto característico en Latinoamérica es la coexistencia de los antiguos y nuevos movimientos sociales, donde se han resignificado las demandas en el espacio de la acción social, retomando asílas demandas históricas. Particularmente, vemos estas continuidades en los movimientos de mujeres durante la dictadura. Por ejemplo, el MEMCH 83 y la AMD incorporaron no solo la lucha por la salud, la vivienda, lo legal y lo laboral, entre otras reivindicaciones, también utilizaron las manifestaciones y ollas comunes como formas de organización y visibilización. Así mismo sucede con el movimiento feminista de la década de 2010: especialmente para el mayo feminista, la integración de demandas transversales desde una perspectiva de género atravesó el movimiento social. 
Otra dimensión importante por destacar es la participación y relación con otras organizaciones, tanto a nivel nacional como global. Dado que el neoliberalismo produce que la lucha social ya no sea enfocada en una sola demanda, sino que interconecta otras asociadas a la búsqueda de la justicia e igualdad social en la vida cotidiana, el movimiento de mujeres se ha vinculado con diferentes agrupaciones (como de familiares de detenidos desaparecidos, pobladores y trabajadores) y ha procurado participar en las redes del feminismo internacional. Repertorios que, por cierto, continuaron durante el Mayo feminista, lo que fortaleció el movimiento y, a su vez, contribuyó a difundir reflexiones y repertorios de acción a nivel trasnacional.

Sin haber analizado otros movimientos feministas importantes de la globalización de las décadas de los 2000 y 2010, podemos observar que la configuración y politización del problema social sobre la violencia de género tiene como motor el reconocimiento de las experiencias muchas veces vividas en el ámbito privado. Los espacios que favorecen la comunicación, la compañía y la igualdad con las otras permiten la colectivización de las experiencias, facilitando los procesos de subjetivación de las vivencias de las violencias vehiculizadas por cada una de las sujetas. Así, se avanza en el reconocimiento del carácter recurrente y generalizado de estas últimas, asentando las bases que permiten y entraman la organización feminista. De esta manera, la historia reciente nos permite reconocer repertorios de acción dialécticos y continuidades en el movimiento feminista que son importantes, donde la fuerza de los diferentes movimientos feministas se encuentra en el saber que existe una otra que refleja tu experiencia.

\section{Referencias bibliográficas.}

Agrupación de Mujeres Democráticas (2015). Quiénes Somos. https://www.mujeresdemocraticas.cl/p/quienes-somos.html

Araujo, K., Guzmán, V. y Mauro, A. (2000), El surgimiento de la violencia doméstica como problema público y objeto de políticas. Revista de la CEPAL 70, 133145. http://repositorio.cepal.org/handle/11362/12204

Bowen Silva, M. (2008). El proyecto sociocultural de la izquierda chilena durante la Unidad Popular. Crítica, verdad e inmunología política. Nuevo Mundo Mundos Nuevos. https://doi.org/10.4000/nuevomundo.13732

De Fina, D. y Figueroa, F. (2019). Nuevos "campos de acción política" feminista: Una mirada a las recientes movilizaciones en Chile. Revista Punto Género, (11), 51-72. https://doi.org/10.5354/0719-0417.2019.53880 
Espeche, C. (2003). Los nuevos sujetos de la protesta social y sus reivindicaciones. Las demandas de participación popular frente al desafío de una profundización de la democracia en América Latina. CLACSO.

Forstenzer, N. (2012). Politiques de genre et féminisme dans le Chili de la postdictature, 1990-2010. Politiques de genre et féminisme dans le Chili de la post-dictature, 1990-2010. Editions L’Harmattan

Forstenzer, N. (2019). Feminismos en el Chile Post-Dictadura: Hegemonías y marginalidades. Revista Punto Género, (11), 34-50. https://doi.org/10.5354/0719-0417.2019.53879

Gárate, M. (2012). La revolución capitalista de Chile (1973- 2004). Universidad Alberto Hurtado.

Garcés, J. E. (2013). Allende y la experiencia chilena: Las armas de la política. Siglo XXI de España Editores.

Godoy Hidalgo, M. y Miranda Pérez, F. (2013). El Programa de Mejoramiento de la Gestión (PMG) de Género en Chile: Impacto sobre las prácticas de los funcionarios. En R. Tamoboleo y R. Bañón (Eds.) Gestión de la Escasez: Participación, Territorios y Estado del Bienestar. Experiencias de Gobernanza y Gestión Pública (pp. 140-147). Ediciones de la Universidad Complutense de Madrid.

Godoy, C. (2013). El estado chileno y las mujeres en el siglo XX. De los temas de la mujer al discurso de la igualdad de géneros. Diálogos Revista Electrónica de Historia, 14(1), 97-123. https://doi.org/10.15517/dre.v14i1.8111

Gross, I. (2015). Por la vida: Las agrupaciones de mujeres durante la dictadura militar chilena. Museo de la Memoria y los Derechos Humanos.

Kirkwood, J. (1986). Ser Política en Chile. Las feministas y los partidos. Cuarto Propio.

Marques-Pereira, B. (2012). Savoir et système de genre au Chili: une connaissance à vocation politique et pragmatique dans un contexte de démocratisation. Revue internationale de politique comparée, 19(3), 127-148. https://doi.org/10.3917/ripc.193.0127

Marugán, B. y Vega, C. (2001): El cuerpo contrapuesto. Discursos sobre la violencia contra las mujeres. En A. Bernárdez (Ed.) Violencia de género y sociedad: una cuestión de poder, Madrid (pp.109-133). Instituto de Investigaciones Feministas y Ayuntamiento de Madrid.

Mejías, C. y Suárez, P. (2015). La configuración de los nuevos movimientos sociales frente a la crisis de lo social. Revista Brasileira de Ciências Sociais 30(89), 159200. http//dx. doi. org/10.17666/3089159-170 
Movimiento feminista chileno y violencias de género. Claves de lectura para entender la acción colectiva en el tiempo presente por Fabiola Miranda Pérez y Maite Henríquez Olivares

Miranda Pérez, F. (2017). Action publique et justice dans le Chili post-dictatorial: Le traitement étatique des violences envers les femmes [Tesis doctoral, Universite Grenoble Alpes].

Miranda Pérez, F, y Godoy Hidalgo, M. (2016). Dispositifs néolibéraux d’autocontrôle de l'État: le programme d'amélioration de la gestion en matière de genre au Chili. En A. Faure, F. Gaudichaud, M. Godoy, F. Miranda y R. Jara (Eds.) Chili actuel. Gouverner et résister dans une société néoliberale. Chile actual. Gobernar y resistir en una sociedad neoliberal (pp. 199-212). Ed. L'Harmattan,

Miranda Pérez, F. y González Badilla, P. (2018). Miradas institucionales sobre la categoría de género en materia de violencias contra las mujeres en Chile. Millcayac - Revista Digital De Ciencias Sociales, 5(9), 141-162. https://revistas.uncu.edu.ar/ojs/index.php/millca-digital/article/view/1357

Montecinos, V. (2003). Feministas e tecnocratas na democratização da América Latina. Revista Estudos Feministas, 11, 351-380. https://doi.org/10.1590/ S0104-026X2003000200002

Ponce, C. (2020). El movimiento feminista estudiantil chileno de 2018: Continuidades y rupturas entre feminismos y olas globales. Izquierdas, (49). http://dx.doi.org/10.4067/s0718-50492020000100280

Prudant Soto, E. (2013). Y entonces estaban ellas. Memoria(s) de las Mujeres Democráticas durante la dictadura. CEIBO.

Reyes-Housholder, C. y Roque, B. (2019). Chile 2018: desafíos al poder de género desde la calle hasta La Moneda. Revista de ciencia política (Santiago), 39(2), 191-216. https://doi.org/10.4067/S0718-090X2019000200191

Ríos Tobar, M., Godoy Catalán, L. y Guerrero Caviedes, E. (2003). ¿ Un nuevo silencio feminista? La transformación de un movimiento social en Chile. Centro de Estudios de la Mujer, Cuarto Propio.

Rojas, C. y Jiles, X. (2019). La extraordinaria acción política protagonizada por el Movimiento Pro- Emancipación de las Mujeres de Chile (MEMCH), 19351949. En R. Álvarez, A. Gálvez y M. Loyola (Eds.), Mujeres y Política en Chile, Siglos XIX y XX (pp. 157-188). Ariadna Ediciones.

Rosemblatt, K. (1995). Por un hogar bien constituido. Disciplina y desacato. Construcción de identidad en Chile, siglos XIX y XX. Ediciones Sur/CEDEM.

Saavedra, V. y Toro, J. (2018). La revuelta feminista: De la lucha de las mujeres a la lucha por una nueva sociedad. En Faride Zerán (Ed.) Mayo Feminista: La Rebelión Contra El Patriarcado (pp. 137-147). LOM. 
Sanz-Gavillon, A.C. (2014). iDemocracia en el país y en la casa! Mouvement des femmes et conceptualisation de la violence de genre dans le Chili de Pinochet. Nuevo Mundo Mundos Nuevos. https://doi.org/10.4000/nuevomundo.66421

Subirats, J. (2001). El análisis de las políticas públicas. Gaceta sanitaria, 15(3), 259264. https://doi.org/10.1016/\$0213-9111(01)71557-9

Urzúa Martínez, S. (2019). Aportes a una etnografía de los movimientos feministas: recursos expresivos en las marchas \#Ni una menos y \#8M en Santiago de Chile. Antípoda. Revista de Antropología y Arqueología, (35), 115-124. https://doi.org/10.7440/antipoda35.2019.06

Valdés, T. (1987). Las mujeres y la dictadura militar en Chile. FLACSO.

Vidal, P. (2014). Unidad Popular y la lucha por la igualdad radical en Chile. Izquierdas (18), 74-93.

Vitale, L. (1996). Cronología comentada del movimiento de mujeres en Chile. Archivo Chile. https://www.archivochile.com/Ideas_Autores/ vitalel/5lvc/05lvcmujer0006.pdf

Zamora, A. (2008). La mujer como sujeto de la violencia de género durante la dictadura militar chilena: apuntes para una reflexión. Nuevo Mundo. https://doi.org/10.4000/nuevomundo.27162

Zárate, M. S. (2008). Por la salud del cuerpo: historia y políticas sanitarias en Chile. En Por la salud del cuerpo: historia y políticas sanitarias en Chile (pp. 284284). Ediciones Universidad Alberto Hurtado.

\section{Dirección de correspondencia:}

Fabiola Miranda Pérez

Contacto: fmiranda@uahurtado.cl 